\title{
POINT: Clinical stage IA non-small cell lung cancer determined by computed tomography and positron emission tomography is frequently not pathologic IA non-small cell lung cancer: The problem of understaging
}

Brendon M. Stiles, MD, Elliot L. Servais, MD, Paul C. Lee, MD, Jeffrey L. Port, MD, Subroto Paul, MD, and Nasser K. Altorki, MD

\begin{abstract}
Objective: There is an increase in interest in limited resection for clinical stage IA non-small cell lung cancer. The purpose of this study was to evaluate the accuracy of the diagnosis of clinical stage IA non-small cell lung cancer when determined by both computed tomography and positron emission tomography scans and to determine factors associated with understaging.
\end{abstract}

\begin{abstract}
Methods: A retrospective review of a prospectively maintained database of patients with non-small cell lung cancer was performed. Patients with clinical stage IA cancer determined by preoperative computed tomography and positron emission tomography scan were reviewed. The influence of the following factors was analyzed with regard to accuracy of clinical staging: tumor size, location, histology, and positron emission tomography positivity.
\end{abstract}

Results: Of the 266 patients identified, cancer was correctly staged in $65 \%$. Final pathologic stages also included IB $(15 \%)$, IIA (2.6\%), IIB (4.1\%), IIIA (4.9\%), IIIB (7.5\%), and IV $(.08 \%)$. Positive lymph nodes were found in $11.7 \%$ of patients. Pathologic T classification changed in $28.2 \%$ of patients. Cancer in patients with clinical tumor size greater than $2 \mathrm{~cm}(\mathrm{n}=68)$ was significantly more likely to be understaged than in patients with tumors $2 \mathrm{~cm}$ or less ( $49 \%$ vs $29 \%, P=.003$ ). Cancer in patients with a positron emission tomography-positive (positron emission tomography $+\mathrm{VE})$ primary evaluation $(\mathrm{n}=218)$ was also more likely to be understaged $(39 \% \mathrm{vs} 15 \%$, $P=.001$ ). Of patients with positron emission tomography $+\mathrm{VE}$ tumors greater than $2 \mathrm{~cm}$, cancer was clinically understaged in $55 \%$, compared with $32 \%$ for positron emission tomography $+\mathrm{VE}$ tumors $2 \mathrm{~cm}$ or less, and only $17 \%$ for positron emission tomography negative $(-\mathrm{VE})$ tumors less than $2 \mathrm{~cm}$.

Conclusion: Clinical stage IA lung cancer is frequently understaged in patients. Size greater than $2 \mathrm{~cm}$ and positron emission tomography positivity are risk factors for understaging. Limited resection should be undertaken with caution in such patients.

Current treatment strategies for non-small cell lung cancer (NSCLC) depend on the accuracy of clinical staging. Although the pathologic stage in the TNM classification more accurately predicts outcomes in patients with NSCLC, ${ }^{1}$ treatment plans are by necessity guided by clinical staging in the TNM classification. The primary objective of preoperative staging is to rule out metastatic or locally advanced disease at presentation. Clinical staging has historically relied on computed tomography (CT) and cervical mediastinoscopy. More recently, positron emission tomography (PET) has become an important noninvasive tool in mediastinal staging. ${ }^{2-7}$

\footnotetext{
From the Division of Thoracic Surgery, New York Presbyterian Hospital-Weill Medical College of Cornell University, New York, NY.

This paper was presented at the 2008 American Association for Thoracic Surgery (AATS) meeting in the point-counterpoint session.

Received for publication May 2, 2008; revisions received Aug 18, 2008; accepted for publication Sept 19, 2008

Address for reprints: Nasser K. Altorki, MD, Division of Thoracic Surgery, Department of Cardiothoracic Surgery, Suite M404, Weill Medical College of Cornell University, 525 East 68th St, New York, NY 10021 (E-mail: nkaltork@med. cornell.edu).

J Thorac Cardiovasc Surg 2009;137:13-9

$0022-5223 / \$ 36.00$

Copyright (C) 2009 by The American Association for Thoracic Surgery

doi:10.1016/j.jtcvs.2008.09.045
}

Unfortunately, there is often a poor correlation between clinical and pathologic staging, even in stage I disease. A prospective trial to evaluate molecular markers of micrometastatic disease, Cancer and Leukemia Group B (CALGB) 9761, also evaluated the correspondence between clinical and pathologic staging in stage I (T1-2, N0) NSCLC. ${ }^{8}$ All patients had CT scans, but only a minority $(12.2 \%)$ had PET scans. Of patients ultimately found to have NSCLC, only $71.6 \%$ had pathologically documented stage I disease. Previous studies have suggested that the addition of PET to CT improves the accuracy of clinical staging across all stages of lung cancer. ${ }^{9-11}$ However, a prospective trial failed to show a significant improvement in accuracy of clinical staging in the subgroup of patients with stage I: $68 \%$ for integrated PET/CT versus $66 \%$ for CT alone. ${ }^{12}$ Given the critical importance of clinical staging in determining further diagnostic and treatment algorithms, it is paramount to critically review current clinical staging techniques and to determine factors associated with understaging.

\section{PATIENTS AND METHODS}

The Thoracic Surgery Tumor Registry at New York Presbyterian Hospital, Weill Medical College of Cornell University, served as the database. 


\section{Abbreviations and Acronyms \\ CALGB $=$ Cancer and Leukemia Group B \\ $\mathrm{CT}=$ computed tomography \\ NSCLC $=$ non-small cell lung cancer \\ PET = positron emission tomography \\ SUV $=$ standardized uptake value \\ VPI $=$ visceral pleural invasion}

A retrospective review of this prospective tumor database identified all patients with pathologically proven NSCLC who were deemed clinically to have stage IA disease, operated on between January 2000 and September 2007. The study included only patients in whom clinical stage IA disease was determined by both CT and PET scan (International Union Against Cancer/American Joint Committee on Cancer staging scheme). Clinical IA stage was determined from a combination of CT scan (including some with contrast and some without) and PET scan findings. If lymph nodes had a maximum standardized uptake value (SUV) of less than $2.0 \mathrm{~g} / \mathrm{mL}$ or were read as "no uptake," they were deemed to be negative, even if greater than $1 \mathrm{~cm}$ by CT scan. Approval for review of hospital records was obtained from the institutional review board, waiving the need for informed consent. Data analyzed included patient age and gender, preoperative radiologic assessments, and tumor location (lobe; central or peripheral) and histology. Tumor size was recorded as the maximum dimension determined from the preoperative CT scan. A tumor was considered peripheral if the center of the tumor was located within the outer one third of the lung field as determined from the radial distance from the hilum to the lung periphery. Surgical data were also reviewed, including the use of mediastinoscopy, extent of surgical resection, and number and stations of lymph nodes resected. Tumor size determined at pathologic review, pathologic nodal classification, and pathologic stage were recorded. Follow-up was obtained through routine office visits or via telephone contact. All patients were followed through September 2007. Statistical analysis was performed using SPSS statistical software (SPSS Inc, Chicago, Ill). Survival was calculated using the Kaplan-Meier method. Categoric data in cross-tabulation tables were compared using Fisher's exact test or Pearson's chi-square test. The independent effect of clinically relevant variables on staging accuracy was evaluated using a logistic regression model.

\section{RESULTS \\ Clinical Findings}

From January 2000 to September 2007, 561 patients with cIA NSCLC underwent surgical resection. Of these 561 patients, 295 did not have PET scans preoperatively. The remaining 266 patients $(37.2 \%$ were men, $62.8 \%$ were women) who had both CT and PET scans for clinical staging served as the basis of the study (Table 1). Their median age was 70 years (range 43-90 years). Mediastinoscopy was performed in $28.2 \%(\mathrm{n}=75)$ of patients. No patient had a positive mediastinoscopy. Anatomic resection was performed in $92.9 \%$ of patients, with $87.6 \%$ undergoing lobectomy. Of patients undergoing lobectomy, $45 \%$ underwent videoassisted thoracic surgery lobectomies. The right upper lobe $(36.2 \%)$ and left upper lobe $(28 \%)$ were the most common lobes resected.
TABLE 1. Patient characteristics $(\mathbf{N}=\mathbf{2 6 6})$

\begin{tabular}{lc}
\hline Median age (range) & 70 y $(43-90$ y) \\
Gender & \\
Male & $99(37 \%)$ \\
Female & $167(63 \%)$ \\
Operation & \\
Wedge & $19(7 \%)$ \\
Segmentectomy & $10(4 \%)$ \\
Lobectomy & $233(88 \%)$ \\
VATS lobectomy & $105(45 \%$ of lobectomies $)$ \\
Bilobectomy & $3(1 \%)$ \\
Pneumonectomy & $1(4 \%)$ \\
Median lymph nodes & 12 \\
Histology & \\
Adenocarcinoma & $88(33 \%)$ \\
Adenocarcinoma with BAC & $123(46 \%)$ \\
BAC & $11(4 \%)$ \\
Squamous & $24(9 \%)$ \\
Other & $20(8 \%)$ \\
Pathologic stage & \\
IA & $174(65 \%)$ \\
IB & $40(15 \%)$ \\
IIA & $7(3 \%)$ \\
IIB & $10(4 \%)$ \\
IIIA & $13(5 \%)$ \\
IIIB & $20(8 \%)$ \\
IV & $2(1 \%)$ \\
\hline
\end{tabular}

VATS, Video-assisted thoracic surgery; BAC, bronchioloalveolar carcinoma.

\section{Pathologic Findings}

A median number of 12 lymph nodes were identified in the pathologic specimens. Approximately two thirds $(65.4 \%)$ of patients with clinical stage IA had pathologic stage IA. Final pathologic stages also included IB $(n=40$, $15.0 \%)$, IIA $(\mathrm{n}=7,2.6 \%)$, IIB $(\mathrm{n}=10,3.8 \%)$, IIIA $(\mathrm{n}=13,4.9 \%)$, IIIB $(\mathrm{n}=20,7.5 \%)$, and IV $(\mathrm{n}=2$, $0.75 \%$ ). Thus, cancer was upstaged to stage II to IV in 52 patients $(19.5 \%)$. Lobar location of the primary tumor had no effect on accuracy of clinical staging. The majority of patients $(79.3 \%)$ had adenocarcinoma or adenocarcinoma with bronchioloalveolar features. Histology also had no statistically significant effect on accuracy of staging.

\section{TNM Correlation}

Pathologic T-stage changed in $28.2 \%$ of patients (Table 2 ). T-stage was upstaged pathologically to $\mathrm{T} 2$ in 52 patients $(19.5 \%)$, of whom $42(15.8 \%)$ had pleural invasion and 10 $(3.8 \%)$ had tumor size greater than $3 \mathrm{~cm}$. Twenty patients $(7.5 \%)$ were noted to have stage $\mathrm{T} 4$ on final pathologic review, all for satellite nodules within the resected lobe. Cancer was upstaged to $\mathrm{T} 3$ in an additional 2 patients $(0.8 \%)$. In regard to pathologic nodal evaluation, 31 patients $(11.7 \%)$ were noted to have metastatic cancer in their lymph nodes. Of the total cohort, $6.8 \%$ had N1 disease and $4.9 \%$ had $\mathrm{N} 2$ disease. Of the 13 patients 
TABLE 2. Pathologic TNM classification of patients

\begin{tabular}{cc}
\hline T stage & \\
T1 & $192(72.2 \%)$ \\
T2 & $52(19.5 \%)$ \\
T3 & $2(0.8 \%)$ \\
T4 & $20(7.5 \%)$ \\
N stage & \\
N0 & $235(88.3 \%)$ \\
N1 & $18(6.8 \%)$ \\
N2 & $13(4.9 \%)$ \\
M stage & \\
M0 & $264(99.2 \%)$ \\
M1 & $2(0.8 \%)$ \\
\hline
\end{tabular}

with $\mathrm{N} 2$ disease, 7 had positive nodes at station 7,4 had nodes at station 5 or 6,4 had nodes at station 2 or 4 , and 1 had nodes at station 9 ( 3 had multilevel disease). Cancer was pathologically upstaged for both $\mathrm{T}$ and $\mathrm{N}$ criteria in 14 patients $(5.3 \%)$. Two patients were noted to have an ipsilateral nodule of identical histology in a different lobe from the primary tumor and were therefore judged to have M1.

\section{Multivariate Analysis}

The following factors were analyzed with respect to predicting the accuracy of clinical staging: patient gender, tumor histology, CT size ( $\leq 2 \mathrm{~cm}$ vs $>2 \mathrm{~cm}$ ), tumor location (central vs peripheral), and PET result (Table 3). Patients were categorized with pIA versus all other pathologic stages. Of the listed clinical factors, CT size and PET status were found to be statistically significant. The estimated hazard ratio of pathologic upstaging for tumors greater than $2 \mathrm{~cm}$ compared with tumors $2 \mathrm{~cm}$ or less was 2.43 , with a $95 \%$ confidence interval of 1.24 to $4.77(P=.01)$. Similarly, the hazard ratio was 3.63 for PET $+\mathrm{VE}$ tumors compared with PET -VE tumors, with a $95 \%$ confidence interval of 1.33 to $9.90(P=.01)$.

TABLE 3. Predictors of pathologic upstaging

\begin{tabular}{lccc}
\hline \multicolumn{1}{c}{ Variables } & Hazard ratio & $\mathbf{9 5} \% \mathbf{C I}$ & $\boldsymbol{P}$ value \\
\hline Gender & & & \\
$\quad$ Female & 1.000 & & \\
$\quad$ Male & 1.657 & $0.878-3.130$ & .119 \\
Histology & & & \\
$\quad$ Adenocarcinoma & 1.000 & & \\
$\quad$ No adenocarcinoma & 0.675 & $0.286-1.592$ & .369 \\
Location & & & \\
$\quad$ Central & 1.000 & & \\
$\quad$ Peripheral & 0.830 & $0.386-1.781$ & .632 \\
PET result & & & \\
$\quad$ Negative & 1.000 & & .012 \\
$\quad$ Positive & 3.626 & $1.329-9.896$ & \\
Clinical tumor size & & & \\
$\quad 0-2 \mathrm{~cm}$ & 1.000 & & \\
$>2 \mathrm{~cm}$ & 2.431 & $1.240-4.766$ & .010 \\
\hline$C I$, Cofide & & & \\
\hline
\end{tabular}

CI, Confidence interval; PET, positron emission tomography.

\section{Effect of Tumor Size}

Patients were divided into 2 groups for analysis on the basis of tumor size on preoperative CT scan: those with tumors less than or equal to $2 \mathrm{~cm}(\mathrm{n}=181)$ and those with tumors greater than $2 \mathrm{~cm}(\mathrm{n}=68)$. Exact preoperative tumor size measurement was not recorded or available in 17 patients. Clinical stage was accurate in $71.3 \%$ of patients with the smaller tumors compared with only $51.5 \%$ in patients with tumors greater than $2 \mathrm{~cm}(P=.003)$. Final pathologic stages are listed in Table 1. The most common upstaging was to pIB. Of patients with tumors $2 \mathrm{~cm}$ or less, $16.6 \%$ were ultimately found to have stage II to IV disease, compared with $29.5 \%$ of patients with tumors greater than $2 \mathrm{~cm}(P=.02)$.

\section{Effect of Positron Emission Tomography Positivity}

We next analyzed the effect of PET scans on the accuracy of clinical staging (Table 4). Cancer was correctly clinical staged as IA in slightly more than $60 \%$ of patients with positive PET scans $(n=218)$. Cancer in patients with negative PET scans $(n=48)$ was significantly more likely to be correctly staged pathologically as IA $(P=.001)$, with an accuracy of $85.4 \%$. Cancer that was upstaged in the majority of patients with PET + VE tumors was reclassified as pIB $(\mathrm{n}=$ $39,17.9 \%$ ). However, cancer in $21.5 \%$ of patients was upstaged to pII-IV disease, compared with only $12.5 \%$ for patients with PET -VE tumors (not significant). Among patients with PET +VE, 194 had an $\mathrm{SUV}_{\max }$ recorded. Of those who were found to have pIA, the median $\mathrm{SUV}_{\max }$ was $2.9 \mathrm{~g} / \mathrm{mL}$ versus $4.5 \mathrm{~g} / \mathrm{mL}$ for the group that was upstaged to higher pathologic stages $(P=.01)$. The median $\mathrm{SUV}_{\text {max }}$ for the whole PET +VE group was $3.4 \mathrm{~g} / \mathrm{mL}$. When patients were divided into groups of low SUV $(<3.4$ $\mathrm{g} / \mathrm{mL})$ or high SUV $(\geq 3.4 \mathrm{~g} / \mathrm{mL})$, differences in staging accuracy were appreciated. Of the low SUV group, $72 \%$ were accurately staged as IA, compared with only $54 \%$ of the high SUV group $\left(P=.008, \chi^{2}\right)$. Upstaging to pII-IV occurred in $14.4 \%$ of the low SUV group compared with $23.8 \%$ of the high SUV group (not significant).

\section{Combined Effect of Tumor Size and Positron Emission Tomography Status}

We next analyzed 4 separate groups of patients according to size and PET criteria: PET $+\mathrm{VE}$ tumors greater than $2 \mathrm{~cm}$; PET + VE tumors $2 \mathrm{~cm}$ or less; PET $-\mathrm{VE}$ tumors greater than $2 \mathrm{~cm}$; and PET -VE tumors $2 \mathrm{~cm}$ or less (Table 5). Of those patients with PET $+\mathrm{VE}$ tumors greater than $2 \mathrm{~cm}(\mathrm{n}=60)$, cancer was correctly clinically staged in only $45 \%$. Of those patients with PET +VE tumors $2 \mathrm{~cm}$ or less $(\mathrm{n}=141)$, cancer was accurately staged as IA $68.1 \%$ of the time. This difference was statistically significant $(P=.002)$. As noted previously, cancer in patients with PET -VE was more accurately staged. Cancer was correctly staged $100 \%$ of the time in those with PET-VE tumors greater than $2 \mathrm{~cm}$ 
TABLE 4. Effect of tumor size and positron emission tomography positivity on pathologic stage

\begin{tabular}{|c|c|c|c|c|c|c|c|c|}
\hline & & IA & IB & IIA & IIB & IIIA & IIIB & IV \\
\hline \multirow[t]{2}{*}{ Size $\left(n=249^{*}\right)$} & $\leq 2 \mathrm{~cm}(\mathrm{n}=181)$ & $71 \%$ & $12 \%$ & $1.7 \%$ & $3.9 \%$ & $4.4 \%$ & $3.9 \%$ & 0 \\
\hline & $>2 \mathrm{~cm}(\mathrm{n}=68)$ & $51 \%$ & $19 \%$ & $5.9 \%$ & $5.9 \%$ & $5.9 \%$ & $10 \%$ & $1.5 \%$ \\
\hline \multirow[t]{2}{*}{$\operatorname{PET}(\mathrm{n}=266)$} & Negative $(\mathrm{n}=48)$ & $85 \%$ & $2.1 \%$ & 0 & $2.1 \%$ & $2.1 \%$ & $8.3 \%$ & 0 \\
\hline & Positive $(n=218)$ & $61 \%$ & $18 \%$ & $3.2 \%$ & $4.6 \%$ & $5.5 \%$ & $7.3 \%$ & $0.9 \%$ \\
\hline
\end{tabular}

PET, Positron emission tomography. *Exact preoperative tumor size was not recorded in 17 patients.

$(\mathrm{n}=8)$, whereas cancer was correctly staged $82.5 \%$ of the time in those with PET - VE tumors $2 \mathrm{~cm}$ or less $(\mathrm{n}=40)$.

\section{Effect of Tumor Location}

Tumor location, central versus peripheral, was determined in 228 patients $(86 \%)$ ). In 38 patients, CT and PET scans were unavailable for review. No definitive determination could be made on the basis of review of radiologic, surgical, and pathologic records in these patients. Among the remaining 228 patients, $181(79 \%)$ had peripheral tumors and $47(21 \%)$ had central tumors. No significant difference was noted between the accuracy of cIA staging: $71 \%$ for peripheral tumors versus $66 \%$ for central tumors. When combining location with PET status, cancer in patients with peripheral PET - VE $(n=37)$ was correctly staged $92 \%$ of the time, compared with $65 \%$ for patients with peripheral PET +VE $(\mathrm{n}=144), 71 \%$ for patients with central PET-V $(\mathrm{n}=7)$, and $65 \%$ for patients with central PET $+\mathrm{VE}(\mathrm{n}=$ 40). This difference was statistically significant $(P=$ .015). Similarly, when combining tumor location with tumor size, differences were noted $(P=.033)$. Peripheral tumors 2 $\mathrm{cm}$ or less $(\mathrm{n}=129)$ were correctly staged $77 \%$ of the time compared with $55 \%$ for peripheral tumors greater than $2 \mathrm{~cm}$ $(\mathrm{n}=42), 71 \%$ for central tumors $2 \mathrm{~cm}$ or less $(\mathrm{n}=31)$, and $55 \%$ for central tumors greater than $2 \mathrm{~cm}(\mathrm{n}=11)$. The difference between the first 2 groups was significant $(P=.01)$.

\section{Peripheral Positron Emission Tomography-Positive Tumors 2 Centimeters or Less}

When evaluating the 3 clinical factors of location, size, and PET status, the most common subgroup of patients included those with peripheral PET $+\mathrm{VE}$ tumors $2 \mathrm{~cm}$ or less $(\mathrm{n}=97,36 \%$ of total). Of these, cancer was correctly staged as IA in $72 \%$. Cancer was upstaged to pIB in $13 \%$. Eleven $(11 \%)$ of these patients had nodal metastases, 6 with N1 disease and 5 with N2 disease. Among the patients with N1 disease, 5 had positive lobar nodes (station 11 or 12) only, and 1 also had a positive station 10 node. For the patients with N2 disease, 3 had positive station 7 lymph nodes, 1 had a positive station 4 lymph node, and 1 had a positive level 5 lymph node.

\section{Survival}

With a median follow-up for surviving patients of 24.3 months, the cohort had a $92.4 \% 5$-year probability of overall survival. As demonstrated in Figure 1, patients found to have pIA disease $(n=174)$ were significantly more likely to be alive at 5 years than were patients with pathologically upstaged cancer $(\mathrm{n}=92 ; 99.4 \%$ vs $79.7 \% ; P<.001$, logrank). There was no significant difference in overall 5-year survival between patients with pIA and pIB disease $(99.4 \%$ vs $96.4 \%)$.

\section{DISCUSSION}

The clinical staging of patients with NSCLC guides patient care and clinical research. A previous report from a prospective, multi-institutional trial demonstrated a poor predictive value of clinical staging systems in stage I NSCLC. ${ }^{8}$ Of patients found to have NSCLC who were enrolled in CALGB 9761, clinical staging was accurate in only $71.6 \%$ of those thought to have stage I disease. Other retrospective studies reported similar rates of inaccurate staging for early-stage NSCLC. ${ }^{13,14}$ Notably, only a minority of patients in these studies had PET scans, $12.2 \%$ in the CALGB 9761 study. PET scans are thought to improve the accuracy of mediastinal staging and diagnosing distant metastatic disease in patients with lung cancer. ${ }^{9-11}$ It is unclear, however, whether PET scan improves the staging accuracy of patients with early-stage NSCLC. One previous study compared staging with CT versus staging with a combination of $\mathrm{CT}$ and integrated PET/CT across all clinical stages. Among patients with clinical stage I disease in that study, accuracies were only $66 \%$ and $68 \%$ for CT and CT/PET, respectively. ${ }^{12}$

Given the critical importance of clinical staging in determining diagnostic and treatment algorithms, we reviewed the accuracy of our own staging of patients with clinical IA NSCLC using the combination of CT and PET scans. Although these patients are uniformly treated surgically, there are likely distinct groups of patients within the population as a whole. This is supported by the fact that the 5 -year survival among patients with cIA is only $61 \%$ as reported in the 1997

TABLE 5. Accuracy of clinical staging for subgroups of patients with cIA

\begin{tabular}{lr} 
PET + VE, $>2 \mathrm{~cm}(\mathrm{n}=60)$ & $45 \%$ \\
PET + VE, $\leq 2 \mathrm{~cm}(\mathrm{n}=141)$ & $68 \%$ \\
PET $-\mathrm{VE},>2 \mathrm{~cm}(\mathrm{n}=8)$ & $100 \%$ \\
PET $-\mathrm{VE}, \leq 2 \mathrm{~cm}(\mathrm{n}=40)$ & $83 \%$ \\
\hline
\end{tabular}

PET, Positron emission tomography. 


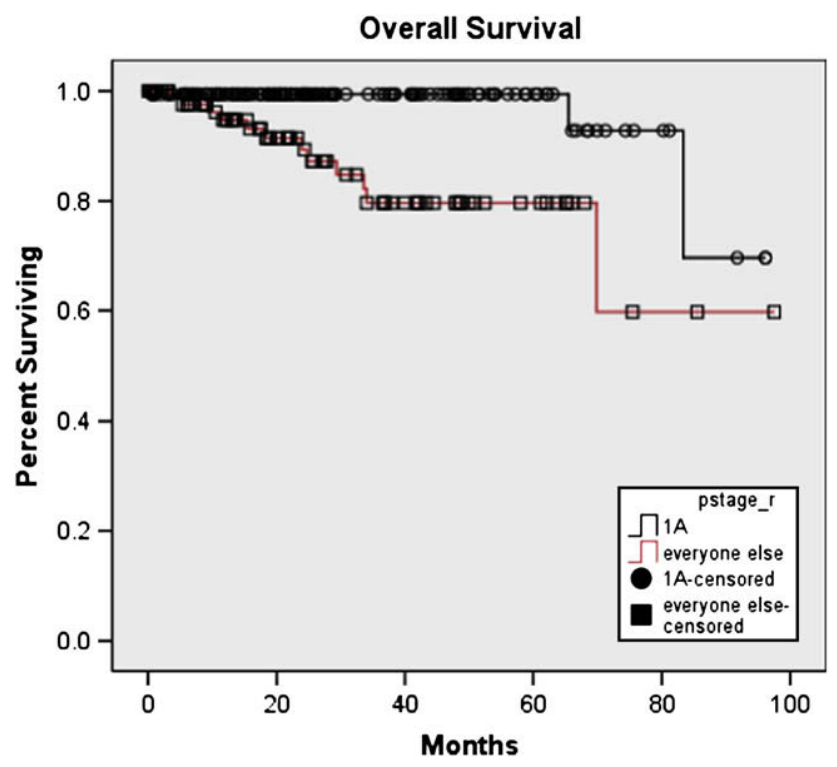

FIGURE 1. Overall survival based on final pathologic stage.

revisions to the International System for Staging Lung Cancer. ${ }^{1}$

In our study of 266 patients with cIA NSCLC, we found only a $65.4 \%$ accuracy of predicting pIA. This is similar to previous surgical series. ${ }^{8,12-14}$ The majority of patients with changed stages $(43 \%)$ had an upstage only to pIB. These patients predominantly had visceral pleural invasion (VPI) by their tumors, with their T stage changing from cT1 to pT2. There have been conflicting reports on the prognostic importance of VPI. VPI likely predicts pleural dissemination of cancer cells and N2 involvement. ${ }^{15-18}$ However, others have shown that VPI does not influence survival in those with tumors less than $3 \mathrm{~cm}$ in size. ${ }^{19}$ Previous staging system revisions demonstrated that patients with pIB disease have worsened survival compared with patients with pIA disease: $57 \%$ versus $67 \%$ at 5 years. ${ }^{1}$ Recent proposals for the revision of $\mathrm{T}$ descriptors focus on tumor size cutpoints but do not address VPI ${ }^{20}$ However, despite potential differences in survival, the treatment algorithm of our patients with stage IB would not have changed even if their disease were correctly staged clinically.

Treatment algorithms may differ in patients with higher stage disease. In the current study, cancer was upstaged to pII-IV in $19.5 \%$ of patients. Without routine PET scans in CALGB $9761,28.4 \%$ of patients were upstaged to pIIIV. ${ }^{8}$ Of our total population of patients whose disease was staged with CT and PET scans, $11.7 \%$ were noted to have metastatic lymph nodes, $6.8 \%$ with $\mathrm{N} 1$ disease and $4.9 \%$ with $\mathrm{N} 2$ disease. This is similar to the reported rate of missed $\mathrm{N} 2$ disease in previous reports. ${ }^{21,22}$ Of the whole cohort, $7.5 \%$ of patients were found to have satellite tumor nodules within the lobe of the lung resected and were therefore upstaged to pT4, pIIIB. Because most patients with N1 disease or T4 disease secondary to satellite nodules typically undergo primary surgical resection, the initial treatment algorithm would have likely only changed in $5.6 \%$ of patients, those with N2 or metastatic disease. Despite the fact that mediastinoscopy was performed in $28 \%$ of the total patient population and in $23 \%$ of patients ultimately found to have N2 disease, mediastinoscopy did not reveal metastatic nodal disease in any of these patients. We have previously reported the important role of mediastinoscopy in further staging clinical stage I (A and B) in patients, particularly in larger tumors, centrally located tumors, and primary tumors with an $\mathrm{SUV}_{\max } 4 \mathrm{~g} / \mathrm{mL}$ or more. Our current report suggests that the recommendation for mediastinoscopy may be less stringent for patients with cIA. Meyers and colleagues ${ }^{23}$ have suggested that routine mediastinoscopy is not cost-effective when patients have already been screened with CT and PET. However, we still favor routine mediastinoscopy in large or central tumors, particularly when associated with PET positivity.

Given that cancer in patients with cIA NSCLC was understaged approximately one third of the time, we sought to determine factors associated with understaging. Tumor size has previously been demonstrated to be a determinant of stage distribution in T1 NSCLC. ${ }^{24}$ Tumors greater than $2.0 \mathrm{~cm}$ are more likely to metastasize to lymph nodes when compared with tumors $2.0 \mathrm{~cm}$ or less. A survival difference is also apparent at this size cutpoint. Data from the International Association for the Study of Lung Cancer Lung Cancer Staging Project showed 5-year survivals of $77 \%$ for the smaller tumors and $71 \%$ for the larger tumors. ${ }^{20}$ For this reason, the Staging Committee recommended changing the $\mathrm{T}$ classification to subclassify $\mathrm{T} 1$ into $\mathrm{T} 1 \mathrm{a}$ $(\leq 2.0 \mathrm{~cm})$ and $\mathrm{T} 1 \mathrm{~b}(>2.0 \mathrm{~cm})$. We therefore examined the accuracy of clinical staging on the basis of CT size of the primary tumor. It is not surprising that staging accuracy was significantly better for the smaller tumors: $71.3 \%$ versus $51.5 \%$. Cancer was upstaged to pII-IV in approximately one third $(29.5 \%)$ of patients with tumors greater than $2 \mathrm{~cm}$.

PET positivity has also been identified as a risk factor for occult mediastinal metastases, recurrence, and death in stage I NSCLC. ${ }^{21,22,25,26}$ We have previously demonstrated that in patients with a PET-VE mediastinum, those with occult N2 metastases had a higher median $\mathrm{SUV}_{\max }$ of the primary tumor than did patients without $\mathrm{N} 2$ disease. ${ }^{21}$ In the current study, we demonstrated that cancer in patients with PET $+\mathrm{VE}$ was accurately staged only $60.6 \%$ of the time, compared with $85.4 \%$ accuracy in patients with PET-VE scans. In particular, cancer in patients with a higher $\operatorname{SUV}_{\max }(\geq 3.4$ $\mathrm{g} / \mathrm{mL}$ ) was likely to be understaged. Only $54 \%$ of these patients had pIA. This is in accordance with previous reports in which high $\mathrm{SUV}_{\text {max }}$ predicted upstaging and poor survival in patients with stage $\mathrm{I}^{21,22,25,26}$

These findings could have a significant effect on the interpretation of studies involving the treatment of stage IA 
NSCLC. Primary radiotherapy with stereotactic body radiation therapy has been demonstrated to be efficacious in patients with medically inoperable disease. ${ }^{27}$ The use of stereotactic body radiation therapy is now being extended to patients who are medically suitable for surgical anatomic resection (Radiation Therapy Oncology Group 0618). Results of this trial and similar trials without a resectional component will be heavily dependent on the accuracy of clinical staging. Similarly, investigations of neoadjuvant chemotherapy and biological therapy continue in early-stage NSCLC. Accurate clinical staging is of paramount importance in assessing the results of these investigational trials.

Clinical staging will also certainly affect surgical decision-making. In particular, there has been resurgent interest in limited resection for early-stage lung cancer. Since the findings from the Lung Cancer Study Group of a 3-fold increase in local recurrence in patients who had sublobar resection, lobectomy has remained the preferential treatment for NSCLC in most centers. ${ }^{28}$ However several groups, particularly in Japan, have since reported good results with sublobar resection for stage I NSCLC. ${ }^{29-31}$ The mode of resection did not affect disease-free survival. Locoregional recurrence was low. However, these studies were limited to patients with T1. The efficacy of sublobar resection is not well established for larger tumors or for those with VPI. In a recent retrospective review of sublobar resection for patients with stage I NSCLC, El-Sherif and colleagues ${ }^{32}$ demonstrated a lower survival with sublobar resection among the subpopulation with stage IB disease: $50 \%$ versus $58 \%$ for lobectomy. There was an increased incidence of VPI in the group of patients undergoing sublobar resection (76\% vs $37 \%)$.

\section{CONCLUSIONS}

CALGB140503, a prospective, randomized study of lobectomy versus sublobar resection for small peripheral NSCLC, has begun to accrue patients in the United States. This trial excludes patients with tumors greater than $2 \mathrm{~cm}$. We expect that the majority of patients entered in this trial will resemble the most common subgroup in the current study: those with peripheral PET $+\mathrm{VE}$ tumors $2 \mathrm{~cm}$ or less. The accuracy of clinical staging in this group of patients was $72 \%$. Intraoperative confirmation of N0 status by sampling station $4,7,5$, or 6 , and 10 lymph nodes would have excluded all of those patients ultimately found to have N2 disease. CALGB140503 will provide further data on the efficacy of lesser resections for cIA NSCLC and should provide further multicenter, prospective data on the accuracy of clinical staging. Until such questions are resolved, limited resection should be undertaken with caution in patients with cIA NSCLC. Certain subgroups demand special consideration. When combining the 2 factors of tumor size greater than $2 \mathrm{~cm}$ and positive PET status, only $45 \%$ of patients with clinical stage IA retained that pathologic stage. These factors should be taken into consideration before including this group of patients in clinical trials.

\section{References}

1. Mountain CF. Revisions in the International System for Staging Lung Cancer. Chest. 1997;111:1710-7.

2. Roberts PF, Follette DM, von Haag D, Park JA, Valk PE, Pounds TR, et al. Factors associated with false-positive staging of lung cancer by positron emission tomography. Ann Thorac Surg. 2000;70:1154-60.

3. Gupta NC, Tamim WJ, Graeber GG, Bishop HA, Hobbs GR. Mediastinal lymph node sampling following positron emission tomography with fluorodeoxyglucose imaging in lung cancer staging. Chest. 2001;120:521-7.

4. Kernstine KH, McLaughlin KA, Menda Y, Rossi NP, Kahn DJ, Bushnell DL, et al. Can FDG-PET reduce the need for mediastinoscopy in potentially resectable nonsmall cell lung cancer? Ann Thorac Surg. 2002;73:394-402.

5. Vesselle H, Pugsley JM, Vallieres E, Wood DE. The impact of fluorodeoxyglucose $\mathrm{F} 18$ positron-emission tomography on the surgical staging of non-small cell lung cancer. J Thorac Cardiovasc Surg. 2002;124:511-9.

6. Gonzalez-Stawinski GV, Lemaire A, Merchant F, O'Halloran E, Coleman RE, Harpole DH, et al. A comparative analysis of positron emission tomography and mediastinoscopy in staging non-small cell lung cancer. J Thorac Cardiovasc Surg. 2003;126:1900-5.

7. Reed CE, Harpole DH, Posther KE, Woolson SL, Downey RJ, Meyers BF, et al. Results of the American College of Surgeons Oncology Group Z0050 trial: the utility of positron emission tomography in staging potentially operable non-small cell lung cancer. J Thorac Cardiovasc Surg. 2003;126:1943-51.

8. D'Cunha J, Herndon JE 2nd, Herzan DL, Patterson GA, Kohman LJ, Harpole DH, et al. Poor correspondence between clinical and pathologic staging in stage 1 non-small cell lung cancer: results from CALGB 9761, a prospective trial. Lung Cancer. 2005;48:241-6.

9. Lardinois D, Weder W, Hany TF, Kamel EM, Korom S, Seifert B, et al. Staging of non-small-cell lung cancer with integrated positron-emission tomography and computed tomography. N Engl J Med. 2003;348:2500-7.

10. Aquino SL, Asmuth JC, Alpert NM, Halpern EF, Fischman AJ. Improved radiologic staging of lung cancer with 2-[18F]-fluoro-2-deoxy-D-glucose-positron emission tomography and computed tomography registration. J Comput Assist Tomogr. 2003;27:479-84.

11. Shim SS, Lee KS, Kim BT, Chung MJ, Lee EJ, Han J, et al. Non-small cell lung cancer: prospective comparison of integrated FDG PET/CT and CT alone for preoperative staging. Radiology. 2005;236:1011-9.

12. Cerfolio RJ, Bryant AS, Ojha B, Eloubeidi M. Improving the inaccuracies of clinical staging of patients with NSCLC: a prospective trial. Ann Thorac Surg. 2005; 80:1207-14.

13. Fernando HC, Goldstraw $P$. The accuracy of clinical evaluative intrathoracic staging in lung cancer as assessed by postsurgical pathologic staging. Cancer. 1990; 65:2503-6.

14. Pisters KM, Ginsberg RJ, Giroux DJ, Putnam JB Jr, Kris MG, Johnson DH, et al. Induction chemotherapy before surgery for early-stage lung cancer: a novel approach. Bimodality Lung Oncology Team. J Thorac Cardiovasc Surg. 2000; 119:429-39.

15. Manac'h D, Riquet M, Medioni J, Le Pimpec-Barthes F, Dujon A, Danel C. Visceral pleura invasion by non-small cell lung cancer: an underrated bad prognostic factor. Ann Thorac Surg. 2001;71:1088-93.

16. Harpole DH Jr, Herndon JE 2nd, Young WG Jr, Wolfe WG, Sabiston DC Jr. Stage I nonsmall cell lung cancer. A multivariate analysis of treatment methods and patterns of recurrence. Cancer. 1995;76:787-96.

17. Kondo H, Asamura H, Suemasu K, Goya T, Tsuchiya R, Naruke T, et al. Prognostic significance of pleural lavage cytology immediately after thoracotomy in patients with lung cancer. J Thorac Cardiovasc Surg. 1993;106: 1092-7.

18. Takizawa T, Terashima M, Koike T, Watanabe T, Kurita Y, Yokoyama A, et al. Lymph node metastasis in small peripheral adenocarcinoma of the lung. J Thorac Cardiovasc Surg. 1998;116:276-80.

19. Hung JJ, Wang CY, Huang MH, Huang BS, Hsu WH, Wu YC. Prognostic factors in resected stage I non-small cell lung cancer with a diameter of $3 \mathrm{~cm}$ or less: visceral pleural invasion did not influence overall and disease-free survival. J Thorac Cardiovasc Surg. 2007; 134:638-43. 
20. Rami-Porta R, Ball D, Crowley J, Giroux DJ, Jett J, Travis WD, et al. The IASLC Lung Cancer Staging Project: proposals for the revision of the T descriptors in the forthcoming (seventh) edition of the TNM classification for lung cancer. J Thorac Oncol. 2007;2:593-602

21. Lee PC, Port JL, Korst RJ, Liss Y, Meherally DN, Altorki NK. Risk factors for occult mediastinal metastases in clinical stage I non-small cell lung cancer. Ann Thorac Surg. 2007;84:177-81.

22. Cerfolio RJ, Bryant AS, Ohja B, Bartolucci AA. The maximum standardized uptake values on positron emission tomography of a non-small cell lung cancer predict stage, recurrence, and survival. J Thorac Cardiovasc Surg. 2005;130:151-9.

23. Meyers BF, Haddad F, Siegel BA, Zoole JB, Battafarano RJ, Veeramachaneni N, et al. Cost-effectiveness of routine mediastinoscopy in computed tomographyand positron emission tomography-screened patients with stage I lung cancer. J Thorac Cardiovasc Surg. 2006;131:822-9.

24. Flieder DB, Port JL, Korst RJ, Christos PJ, Levin MA, Becker DE, et al. Tumor size is a determinant of stage distribution in $\mathrm{t} 1$ non-small cell lung cancer. Chest. 2005; 128:2304-8

25. Goodgame B, Pillot GA, Yang Z, Shriki J, Meyers BF, Zoole J, et al. Prognostic value of preoperative positron emission tomography in resected stage I non-small cell lung cancer. J Thorac Oncol. 2008;3:130-4.
26. Hanin FX, Lonneux M, Cornet J, Noirhomme P, Coulon C, Distexhe J, et al. Prognostic value of FDG uptake in early stage non-small cell lung cancer. Eur J Cardiothorac Surg. 2008 [Epub ahead of print].

27. Timmerman RD, Park C, Kavanagh BD. The North American experience with stereotactic body radiation therapy in non-small cell lung cancer. J Thorac Oncol. 2007;2:S101-12

28. Ginsberg RJ, Rubinstein LV. Randomized trial of lobectomy versus limited resection for T1 N0 non-small cell lung cancer. Lung Cancer Study Group. Ann Thorac Surg. 1995;60:615-23.

29. Okada M, Sakamoto T, Nishio W, Uchino K, Tsubota N. Characteristics and prognosis of patients after resection of nonsmall cell lung carcinoma measuring $2 \mathrm{~cm}$ or less in greatest dimension. Cancer. 2003;98:535-41.

30. Kondo D, Yamada K, Kitayama Y, Hoshi S. Peripheral lung adenocarcinomas: $10 \mathrm{~mm}$ or less in diameter. Ann Thorac Surg. 2003;76:350-5.

31. Bando T, Yamagihara K, Ohtake Y, Miyahara R, Tanaka F, Hasegawa S, et al. A new method of segmental resection for primary lung cancer: intermediate results. Eur J Cardiothorac Surg. 2002;21:894-900.

32. El-Sherif A, Gooding WE, Santos R, Pettiford B, Ferson PF, Fernando HC, et al Outcomes of sublobar resection versus lobectomy for stage I non-small cell lung cancer: a 13-year analysis. Ann Thorac Surg. 2006;82:408-16. 